\title{
SPONTANEOUS TRIPLET PREGNANCY - A CASE REPORT
}

\author{
WAZED $F^{1}$, SULTANA N ${ }^{1}$, BANU LA ${ }^{1}$, NASRIN N$^{2}$, SULTANA HS ${ }^{3}$, BEGUM A $^{1}$
}

\begin{abstract}
:
A patient age 25 years para 1, $2^{\text {nd }}$ gravida with previous history of Caesarean Section (delivered a still born baby due to APH) was admitted into DMCH with 33 weeks pregnancy and back pain for 5 days. She was not in regular antenatal check up but completed immunization against tetanus. She was a regularly menstruating woman. She noticed undue enlargement of abdomen in her last trimester with excessive fetal movement. On examination, her BP was found 100/70 $\mathrm{mmHg}$, with bilateral leg oedema. SFH was $36 \mathrm{wks}$ size \& fetal heart sound was audible at multiple sites. Her USG shows triplet live pregnancy of 33-34 weeks duration. Elective C\S was done after 2 weeks at 06.04.2010. Three live birth premature babies were delivered. Weight of the babies was $2.1 \mathrm{~kg}, 2 \mathrm{~kg}, 1.9 \mathrm{~kg}$. After 7 days of hospital stay, the patient was discharged with three healthy kids and great pleasure.
\end{abstract}

Key words: Triplet pregnancy, Ceasarean section.

J Dhaka Med Coll. 2009; 18(1) : 88-90

\section{Introduction:}

A multiple birth occurs when more than one foetus is carried out to term in single pregnancy. Different names for multiple births are used, depending on the number of offspring. Common multiples are twins \& triplets. Multiple birth siblings are either monozygotic or dizygotic. The former results from a single fertilized egg or zygote splitting into two or more embryos, each carrying the same genetic material. Siblings created from one egg are commonly called identical. Since identical multiples share the same genetic material, they are almost always same sex. In rare cases, how ever, a fertilized egg will have an extra gender typing chromosome. These fertilized eggs or zygotes can be XXX, XXY or $\mathrm{XYY}$. When a zygote with XXY splits it will end with one $X X$ and one $X Y$ twin who are genetically identical in every way but sex. Dizygotic instead result from multiple ova being ripened and released in same menstrual cycle by a woman's ovaries, which are then fertilized to grow into multiples no more genetically alike than ordinary full siblings. Multiples called polyzygotic represent some combination of dizygotic \& identical siblings. For example: A set of triplets maybe composed of identical twin from one egg \& a third sibling from second egg ${ }^{1}$. According to Hellens law multiple births naturally at approximately the rate of twins: 1/89(about $1.1 \%$ )of singleton birth.Triplets: 1 / $89^{2}=1 / 7921$ (about0.013\%)of singleton birth . But a traditional approximation of the incidence of multiple pregnancies is as follows twin 1:80, tripiets $1: 6400^{2}$. The incidence of triplet pregnancies has risen steadily primarily because of the development of assisted reproductive technology (ART). Although the number of spontaneously conceived triplets increased slightly in the past 30 years, this only account for about $10 \%$ of the increase in multiple birth ${ }^{3}$. The rate of triplets increased from 29/1,00,000 live birth in 1971 to $174 /$ $1,00,000$ live birth in $1997-4,5,6,7$. The rise in multiple pregnancies has led to the concomitant increase in low birth weight infant born at younger gestational age ${ }^{8}$. Some studies postulate that at least $5 \%$ of all triplets pregnancies are jeopardized by life threatening fetal complication in at least one of the foetuses ${ }^{9,10}$.

\section{Case report:}

A 25 years old woman having para $1,2^{\text {nd }}$ gravida with previous Caesarean Section

1. Assistant Professor, Department of Obstetrics \& Gynaecolgy, Dhaka Medical College and Hospital, Dhaka.

2. Assistant Professor, Department of Obstetrics \& Gynaecolgy, Dhaka National Medical College and Hospital, Dhaka.

3. Junior Consultant, Department of Obstetrics \& Gynaecolgy, Dhaka Medical College Hospital, Dhaka.

Correspondence : Dr. Feroza Wazed 
operation and delivered a still born baby (due to APH ) was admitted in DMCH with 33 weeks pregnancy with back pain for 5 days. She was not in a regular antenatal check up (ANC) but completed immunization against tetanus. She was a regularly menstruating woman. She noticed undue enlargement of abdomen in her last trimester. For thy last 5 days of her admission she developed low back pain radiating to both thighs. She also felt excessive fetal movement. That is why she was admitted into $\mathrm{DMCH}$. She gave the history of triplets pregnancy in her family. On examination, her $\mathrm{BP}$ was $100 / 70 \mathrm{mmHg}$, and having moderate anaemia, bilateral leg oedema. Her SFH was 36 weeks size, foetal heart sound is heard at multiple sites. Excessive foetal parts were palpable, polyhydramnios was present. Patient was not in labour. Other systems revealed no abnormality. Ultrasonoram was done which shows triplet live pregnancy of about 33-34 weeks duration. According to biparietal diameter (BPD), $1^{\text {st }}$ and $2^{\text {nd }}$ baby correspond to 34 weeks size and $3^{\text {rd }}$ baby 32 weeks 5 days size. For lung maturation of foetuses prophylactic steroid was given to the mother. The patient was follow uped carefully for next two weeks with complete bed rest. The period was uneventful. There was no scar tenderness. Elective Caesarean Section was done and 3 alive babies (two male \& one female) were delivered with 10/10 Apgar score. Babies were in separate amniotic cavity but 3 placentas were fused in margin resembling single placenta with 3 centrally placed umbilical cords. The weight of the babies were $2.1 \mathrm{~kg}, 2 \mathrm{~kg}, 1.9 \mathrm{~kg}$ respectively. After proper haemostasis, uterus and abdomen were closed in layers. The post operative period of this patient was uneventful. Postnatally 2 of the babies were normal but $3^{\text {rd }}$ one developed mild jaundice and was admitted into SCABU for better management. After 7 days of hospital stay, the patient was discharged with three healthy kids.

\section{Discussion:}

This is a case of triplet pregnancy, which is spontaneous, not due to ovulation induction at 33 weeks of pregnancy. High order of multiple births ( 3 or more offspring in one birth) may result in a combination of fraternal and identical siblings. Spontaneous triplets derive from one two or three ova In the simplest case each ovum in fertilized separately, giving rise to three zygotes the trichorionic triplet, one of the zygote should have undergone splitting which leads to either a dichorionic or a monochorionic set of twin. Dizygotic triplet thus may comprise either trichorionic triplet or a set of monochorionic twin plus a singleton. The monochorionic set,however may be either diamniotic or monoamniotic. Finally monozygotic triplet presumably result from splitting of a single zygote into two monozygotic cell masses of which one undergoes a subsequent secondary division .Also it might be that both monozygotic cell masses undergo a secondary division into monozygotic quadriplet and the monozygotic triplet set is a result of resorption of one of the quadriplet.

The figure shows -

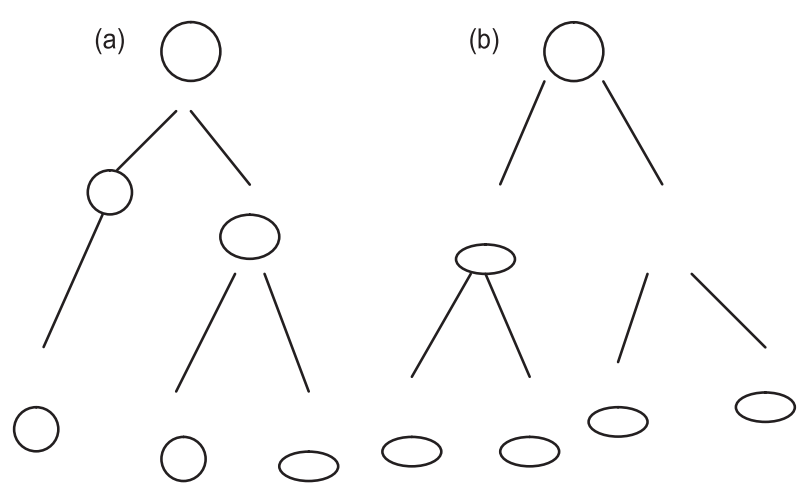

Monozygotic triplet: (a) Secondary division of one of the cell mass which resulted from splitting of a single zygotic, (b) Secondary division of both cell masses but one of the resultant quadruplet under go resorption.

Chorionicity \& zygotic in a population based on series of 31 naturally conceived triplet set-

Trichorionic Dichorionic Monochorionic

$$
\begin{aligned}
& \mathrm{MZ}-\_-0-1 \longrightarrow 5 \\
& \mathrm{DZ}-4-13-0 \\
& \mathrm{TZ}-\_-8-1-0 \\
& \text { ** } \mathrm{MZ}=\text { Monozygotic } \\
& \text { ** DZ = Dizygotic } \\
& * * \mathrm{TZ}=\text { Trizygotic }
\end{aligned}
$$


Our triplet pregnancy may be anyone of two categories. But question is sex differentiation. Chorionicity of this pregnancy was not determined. Depending on chorionicity growth discordance may occur. Here in this case placental fusion was there. A large placenta seems to be single one due to fusion of margins of 3 placentae with centrally placed 3 umbilical cords. But they were in 3 separate sacs. It would appear that total placental fusion may predispose one triplet to restriction. Growth discordance $>20 \%$ is important. In dichorionic triamniotic growth discordance 35\% and trichorionic triamniotic growth discordance is $31 \%^{11}$. But after birth of these babies no visible growth discordance was present. It is an unusual. Multiple gestation pregnancies with more than two foetuses are at a large risk of foetal and maternal complications that may threaten the survival of the mother or of one or more foetuses ${ }^{12-18}$. Though our patient had a history of Caesarean Section operation, even with the triplets, she had no multiple pregnancy related complications and no scar tenderness. Multiple pregnancies in human are invariably born prior to 38 weeks of gestation. 36 weeks is average for a twin birth, and 32 weeks for triplets. But our case overrun the average weeks of born. Babies born from multiple birth pregnancies are more likely to result in premature birth than those from single pregnancies. $51 \%$ of twins and $91 \%$ of triplets are born preterm, compared to $9.5 \%$ in single tones our babies were premature also ${ }^{19}$. Such preterm birth tends to have a lower birth weight and these babies were born with the birth weight that is of $2.1 \mathrm{~kg}, 2 \mathrm{~kg}, 1.9 \mathrm{~kg}$ respectively. All the babies were referred to SCABU for their prematurity. Among them two were normal but third one was a little bit icteric and reluctant to feed.

\section{Conclusion:}

Triplet pregnancy demonstrates good survival rate with very low associated morbibdity. Naturally conceived triplet sets contain significant number of monozygotic triplets. Evidence of tri and dizygotic triplets is rare. But still it is happening with successful live birth. Triplets will have been reduced to twins or a single foetus by medical intervention, referred to as multifoetal pregnancy reduction, early in the pregnancy. The outcome of which will be comparatively better.

\section{References:}

1. Multiple births. From Wikipedia: the free encyclopedia .

2. Bush M, Pernoll ML. Multiple Pregnancy. 2006;

3. Clinical Dilemma in triplet pregnancy. J Perinatol.

4. Counting FC, MacDonald PC, Leveno J, Gilstrap K. eds. Multiple pregnancies In: Williams' Obstetrics. $19^{\text {th }}$ ed. Norwalk: Appleton and Lange; 1993. p.891-8.

5. Chitkara U, Berkowitz RL. Multiple gestations. In: Gabbe SG, Niebyl JR, Simpson JL, eds. Obstetrics: normal and problem pregnancies. $3^{\text {rd }}$ ed. New York: Livingstone; 1996. p.821-62.

6. Benirschke K. Multiple question: incidence, etiology and inheritance. In: Creasy RK, Resnik P. eds. Maternal fetal medicine: principles and practice. $4^{\text {th }}$ ed. Philadelphia: Saunders; p.589615.

7. Botting BJ, Davies IM, Macfarlane AJ. Recent trends in the incidence of multiple births and associated mortality. Arch Dis Child. 1997; 284: 299-300.

8. Warner BB, Kiely JL, Donovan EF. Multiple births and outcome. Clin Perinatol. 2000; 27: 347-61.

9. Borlum KG. Third trimester fetal death in triplet pregnancies. Obstet Gyecol. 1991; 77: 6-9.

10. Gonen R, Heyman E, Asztalos E, Milligan JE. The outcome of gestation complicated by fetal death. Obstet Gynecol. 1999; 75: 175-8.

11. Triplet pregnancies and their consequence. Edited by Keith HG and Stein IB.

12. Albrecht JL, Tomich PG. Obstetrics: the maternal and outcome of triplet gestation. Am J Obstet. 1996; 174: 1551-6.

13. Malone FD, Kaufman GE, Chelmow D, Athanassious A, Nores JA, D'Alton ME. Maternal morbidity associated with triplet pregnancy. Am J Perinatol. 1998; 15: 73-7.

14. Thorp JM, Tumey LA, Bowes WA. Outcome of multiple gestation: a case study. J Marten Fet Med. 1994; 3: 23-6.

15. Chervenak FA, Johnson RE, Youcha S, Hobbins JC, Berkowitz RI. Intrapartum management of twins' gestation. Obstet Gynecol. 1985; 119-24.

16. MacGill VI. Some observations on the incidence of preeclampsia. J Obstet Gynecol. 1958; 65: 536-9.

17. McMullan PF, Norman RJ, Marivate M. Pregnancy induced hypertension in twin pregnancy. J Obstet Gynecol. 1984; 91: 240-3.

18. Chitkara U, Berkowitz GS, Levine R et al. Twin pregnancy: routine use of ultrasound examination in the prenatal diagnosis of intrauterine growth retardation and discordant growth. Am J Perinatol. 1985; 2: 49-54.

19. Alexander G, Martin J, Papiernik E. What are the fetal growth patterns of singletons, twins, and triplets in the United States? Clin Obstet Gynecol. 1998; 41(1): 114-125. 